\title{
Performance of a novel system for high-resolution tracking of marine fish societies
}

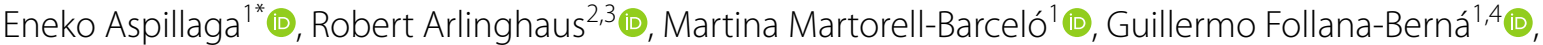 \\ Arancha Lana', Andrea Campos-Candela ${ }^{1,2}$ (i) and Josep Alós ${ }^{1}$ (D)
}

\begin{abstract}
Recent advances in tracking systems have revolutionized our ability to study animal movement in the wild. In aquatic environments, high-resolution acoustic telemetry systems make it technically possible to simultaneously monitor large amounts of individuals at unprecedented spatial and temporal resolutions, providing a unique opportunity to study the behaviour and social interactions using a reality mining approach. Despite the potential, high-resolution telemetry systems have had very limited use in coastal marine areas due to the limitations that these environments pose to the transmission of acoustic signals. This study aims at designing and testing a high-resolution acoustic telemetry system to monitor, for the first time, a natural fish population in an open marine area. First, we conducted preliminary range tests and a computer simulation study to identify the optimal design of the telemetry system. Then, we performed a series of stationary and moving tests to characterize the performance of the system in terms of positioning efficiency and precision. Finally, we obtained a dataset corresponding to the movements of 170 concurrently tagged individuals to demonstrate the overall functioning of the system with a real study case of the behaviour of a small-bodied coastal species. Our results show that high-resolution acoustic telemetry systems efficiently generate positional data in marine systems, providing a precision of few meters, a temporal resolution of few seconds, and the possibility of tracking hundreds of individuals simultaneously. Data post-processing using a trajectory filter and movement models proved to be key to achieve a sub-meter positioning precision. The main limitation detected for our system was the restricted detection range, which was negatively affected by the stratification of the water column. Our work demonstrates that high-resolution acoustic telemetry systems are an effective method to monitor the movements of free-ranging individuals at the population level in coastal sites. By providing highly precise positioning estimates of large amounts of individuals, these systems represent a powerful tool to study key ecological processes regarding the social interactions of individuals, including social dynamics, collective movements, or responses to environmental perturbations, and to extend the studies to poorly studied small-sized species or life-stages.
\end{abstract}

Keywords: Acoustic telemetry, High-resolution tracking, Movement ecology, Reality mining

*Correspondence: eneko.aspillaga@gmail.com

1 Institut Mediterrani d'Estudis Avançats (IMEDEA, UIB-CSIC), Esporles, Balearic Islands, Spain

Full list of author information is available at the end of the article

\section{Background}

Reality mining is the collection and analysis of machinesensed data pertaining to animal social behaviour, with the goal of identifying predictable patterns of movement and behaviour within populations $[1,2]$. New high-resolution tracking technologies, based on Global Positioning Systems (GPS) in terrestrial environments 
and ultrasound biotelemetry in aquatic systems, make it possible to gather with exceptional detail the social and environmentally driven dynamics of large amounts of individuals, making reality mining of animal societies feasible $[2,3]$. The possibility of generating precise and extensive movement and social data allows us to address key ecological and behavioural questions that were before out of our reach, such as the formation of social dynamics and their temporal variability [4], the emergence of collective movements [5], and the response of natural populations to environmental changes or human impacts [3].

In aquatic systems, acoustic telemetry is the most widely used technique to study the movement and behaviour of free-ranging organisms [6]. Acoustic tracking consists of equipping the studied organisms with transmitters that emit coded acoustic signals; which are, in turn, detected by an array of acoustic receivers [7]. The conventional approach to study the movement and behaviour of fish based on acoustic tracking is analysing presence/absence patterns of detections, using the known position of the receivers as proxy of positional data [8]. Different analytical approaches have been developed to reduce or accommodate positional uncertainty to obtain more accurate latitudinal and longitudinal positions from acoustic telemetry, such as different types of discretized interpolations (e.g., Centres of Activity [9]), state-space models $[10,11]$, graph theory [12], or synthetic generation of random paths [13]. Unfortunately, none of these methods can generate the accurate and precise positional data required to measure social behaviour in a large number of individuals, limiting the use of acoustic tracking in reality mining approaches for fish societies.

New developments in acoustic tracking technology have recently switched the traditional presence/absence approach of acoustic telemetry to the high-resolution data generation in freshwater systems [14-16]. First, signal positioning systems based on hyperbolic tri- or multilateration notably reduce the positioning uncertainty by estimating the position of transmitters from the difference in time of arrival of detections in receivers, with an error ranging from some centimetres to few metres (e.g., Vemco Positioning System [17], Lotek MAP system [18], YAPS [19]). Second, thanks to the implementation of the Binary Phase-Shift Keying (BPSK) coding system, transmitters emit signals of less than $1 \mathrm{~ms}$ [20] that increase the temporal resolution of trajectories by providing positions every few seconds and allow to track hundreds or thousands of individuals simultaneously without collision issues [21]. In contrast, classic acoustic telemetry techniques using the Pulse Position Modulation (PPM) coding system offer positions with a resolution of few minutes to hours [11], notably impacting the reconstruction of trajectories [22] and our ability to detect short-term ecological processes. Recent studies have assessed the performance of high-resolution acoustic tracking systems, which combine signal positioning and BPSK coding systems, covering entire lakes $[14,23]$ and river sections [24], demonstrating the potential of this technique to generate trajectories with the high spatial and temporal resolution required by the reality mining approach.

High-resolution acoustic telemetry systems have not yet been applied in marine systems due to the challenges that this environment presents in terms of sound propagation. The BPSK coding system used by these systems works at relatively high frequencies (e.g. Vemco High Residency system: 180 and $307 \mathrm{kHz}$; Lotek JSATS system: $416 \mathrm{kHz}$ ), which suffer a high attenuation by absorption in saltwater due to its viscosity [25]. For this reason, the acoustic range at which signals are detected is much smaller in marine environments, imposing a big restriction regarding the number of the receivers required to effectively cover a given area and the subsequent impact on the cost of the experiment. Moreover, many other factors are also known to affect the transmission efficiency of acoustic signals, such as the stratification of the water column (i.e., the presence of a thermocline), environmental noise due to abiotic (waves, wind) and biotic factors (i.e., biological noise) or the habitat heterogeneity [26, 27]. Therefore, high-resolution telemetry systems require a thoughtful design and test before being definitively used in marine environments.

The main objective of this study was to design and test a high-resolution acoustic telemetry system to conduct a reality mining experiment with a natural fish population in an open marine area. We combined preliminary range tests and computer simulation analysis to choose the optimal design of the acoustic array. After installing the array, a series of positioning tests were conducted to characterize the performance of the system in terms of positioning efficiency and error. We also present a subsample of empirical data from fish individuals that were tagged within the array to demonstrate the efficiency of the system to monitor the fine-scale movements of a local fish-population and to provide a range of applications of this technology to study the behavioural and social component of marine fish.

\section{Materials and methods}

\section{Acoustic telemetry system}

We used the JSATS high-resolution tracking system (Juvenile Salmon Acoustic Telemetry System, developed by the Pacific Northwest National Laboratory [28]) from Lotek Wireless Inc. (Canada) to evaluate its performance in a marine environment. This system was composed by 
L-AMT series acoustic micro-transmitters (frequency: $416.7 \mathrm{kHz}$, power output: $+158 \mathrm{~dB}$ ) and WHS-4250L autonomous receivers. The JSATS system is ideally applied to free-ranging fish to generate accurate twodimensional data at an affordable cost $(\sim 165 €$ per transmitter). In addition, the small size of transmitters allows for tracking almost all range of fish sizes, making the systems unique to perform reality mining approaches. At present, L-AMT transmitters are not manufactured with equipped sensors (e.g., depth, activity). We considered four different transmitter models: L-AMT-1.421, L-AMT-5.1B, L-AMT-5.2, and L-AMT-8.2 (weight in air: $0.32,0.6,1.1$, and $3.5 \mathrm{~g}$; emission period: $10,5,5$, and $2 \mathrm{~s}$; battery life: 72, 95, 81 and 218 days, respectively). WHS-4250L receivers, which are equipped with internal acoustic transmitters, were programmed to emit beacon signals with a period of $15 \mathrm{~s}$ to monitor the functionality of the system and to synchronize internal clocks before applying the positioning algorithm. Detection data from receivers were downloaded using the WHS Host software and the $2 \mathrm{D}$ positions were estimated using the
UMAP acoustic positioning software, both provided by the manufacturer. All the data were later imported to the $\mathrm{R}$ computing environment [29], where further data management, cleaning, analysis and visualization tasks were performed.

\section{Study site and target species}

All the experimental testing using the JSATS system was carried out in the Bay of Palma marine reserve (Mallorca, Balearic Islands, Spain, Fig. 1). We identified a sandy area near the coast in the no-take area of the reserve that was suitable for our study due to three characteristics: (1) it had a relatively small size $(600 \mathrm{~m}$ long $\times 270 \mathrm{~m}$ wide, total area: 12.5 ha, depth range: $11-19 \mathrm{~m}$ ), so it could be covered by a reasonable number of acoustic receivers; (2) it was inhabited by a dense population of the pearly razorfish (Xyrichtys novacula), the target species of our ongoing research project; and (3) it was clearly delimited by a Posidonia oceanica seagrass meadow, which presumably acted as a natural barrier preventing tagged

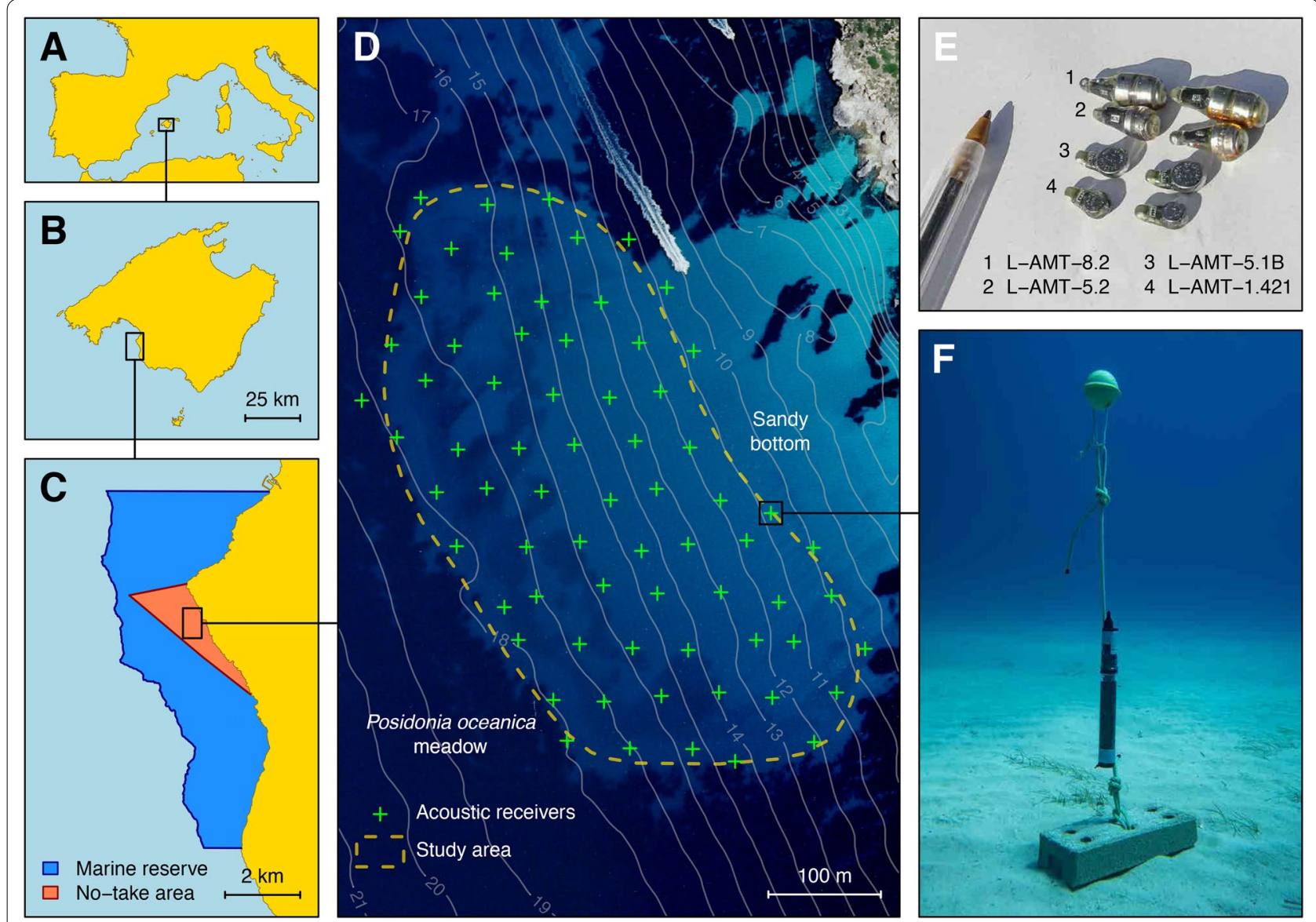

Fig. 1 Location of the study area within the Bay of Palma marine reserve, NW Mediterranean Sea (a-c), definitive acoustic array of WHS-4250L receivers (d) and pictures of the used JSATS transmitter models (e) and the method to install acoustic receivers (f) 
individuals from leaving the study area (Fig. 1a-d). The pearly razorfish is a small-bodied wrasse (average size of females: $144 \mathrm{~mm}$, males: $196 \mathrm{~mm}$ ) that inhabits shallow sandy bottoms of temperate and tropical areas and is exploited by recreational fisheries [30].

\section{Characterization of the acoustic range}

As a first step to explore the performance of the JSATS system, a standard acoustic range test was conducted in the study area to characterize the probability of detecting a signal depending on the distance to the receivers [31]. A stationary receiver was placed in the middle of the study area, at $1.5 \mathrm{~m}$ from the bottom and with the hydrophone pointing upwards, attached to a mooring with a line and buoy. Seven transmitters were attached to a second line that was moored at 10 different distances from the receiver $(5,10,20,30,50,75,100,135,160$ and $200 \mathrm{~m})$ for periods of 13-18 min. Once downloaded, detection data were pooled into 1-min intervals and the detection efficiency was calculated for each transmitter as the proportion of the emitted signals (estimated from the emission period) detected by the receiver. Finally, the decay of the detection probability with distance was modelled by fitting a mixed effects logistic regression, considering transmitter's id as a random factor to account for the possible variability between transmitters. The non-linear regression was fitted using the $n l m e$ package for $\mathrm{R}$ [32].

\section{Testing the optimal design of a JSATS receiver array}

We carried out a computer simulation analysis to identify the most suitable array design that would effectively cover the study area and maximize the positioning efficiency, considering that signals must be detected by at least three receivers to allow hyperbolic positioning. We simulated a set of different arrays with different grid shapes and between-receiver distances. Three grid-shapes were tested (Additional file 1): equilateral triangular (i.e., receivers equally separated generating a grid of equilateral triangular cells), isosceles triangular (i.e. receivers generating a grid of isosceles triangles of equal height and width), and rectangular (i.e., receiver on a grid of rectangles of equal height and width). Different grid versions of each shape were generated by varying the between-receiver distances, using values ranging from 5 to $100 \mathrm{~m}$. Generated grids were cropped to fit the study area and restricted to use a maximum of 70 receivers (our maximum number of available units). Then, we simulated 12 random trajectories of fishes moving according to a home-range behaviour (Additional file 2). Trajectories were generated using a random walk movement model weighted by an Ornstein-Uhlenbeck process [11]. The two main parameters that defined the characteristics of each track, the radius $(r)$ and the rate of exploitation $(k)$ of the home range, were randomly sampled from uniform distributions of values between $50-200$ and $10^{-6}-10^{-3}$, respectively, according to previous real data generated for the study species in open access fisheries [30]. Trajectories were generated with a position every $5 \mathrm{~s}$, simulating the signal emission of JSATS transmitters, and a total duration of $6 \mathrm{~h}$. Each simulated trajectory was combined with the empirical acoustic range model to obtain a possible realization of the detection pattern in each receiver array. The detection probability of each signal was estimated by applying the acoustic range model to the distances between its position and all the receivers the array. Then, the detection event in each receiver was randomly sampled from a binomial distribution defined by the estimated detection probability. Finally, the potential positioning efficiency of each array was calculated as the percentage of signals in trajectories that were detected by three or more receivers as required for the proper positioning of the signal.

\section{Deployment and performance of the JSATS array}

As part of a larger acoustic telemetry project, an array formed by 70 acoustic receivers was placed in the study area following the results from the preliminary range tests and the computer simulation analysis (Fig. 1d). Receivers were installed at approximately $50 \mathrm{~m}$ from each other forming an equilateral triangular pattern, attached to a structure formed by a mooring, a line and a sub-superficial buoy at $1.5 \mathrm{~m}$ from the bottom with the hydrophone pointing to the surface (Fig. 1e). The structures were dropped from a boat and positions were registered using a Trimble GeoHX differential GPS (accuracy: $\pm 0.2 \mathrm{~m}$ ). A HOBO Pendant Temperature/Light data logger was placed in the centre of the receiver array (depth: $14 \mathrm{~m}$ ) to measure water temperature $\left({ }^{\circ} \mathrm{C}\right)$ every $10 \mathrm{~min}$. The array was placed in April 302019 and definitively retrieved in September 30 2019. Between June 5 and 10 2019, receivers were temporally retrieved for maintenance purposes.

Three types of positioning tests (fixed, drift and towed) were carried out in the definitive JSATS receiver array. Fixed tests were conducted by placing transmitters in stationary moorings randomly distributed within the array. A total of 71 deployments of fixed tests with a duration of $34 \pm 14$ min (mean $\pm S D$ ) were performed on 6 different days from June 4 to July 3 2019. Drift and towed tests were carried out by attaching five transmitters to a weighted line that was hung on one side of the boat keeping the transmitters at $2 \mathrm{~m}$ from the bottom. Two drift tests were conducted on the same day (May 16 2019) by leaving the boat drifting with the wind across the receiver array for periods of 17 and $15 \mathrm{~min}$ and at speeds of $0.50 \pm 0.03 \mathrm{~m} \mathrm{~s}^{-1}$ and $0.53 \pm 0.08 \mathrm{~m} \mathrm{~s}^{-1}$ (mean $\pm S D$ ). Two towed tests were performed on two different days 
(May 16 and September 28, 2019) by driving the boat within the array for periods of 27 and $54 \mathrm{~min}$ and at mean speeds of $1.4 \pm 0.4$ and $0.6 \pm 0.2 \mathrm{~m} \mathrm{~s}^{-1}$, respectively. The position of fixed tests and the boat tracks during drift and towed tests were recorded using a regular portable GPS (Garmin GPS73, accuracy: $\pm 3-5 \mathrm{~m}$ ).

\section{Tagging fish with JSATS AMT transmitters}

To analyse the efficiency of the acoustic array to monitor the movements of a free-ranging fish population, a sample dataset was retrieved from the telemetry experiment that was performed with the installed acoustic array. The dataset contained all the positions obtained in the same day (May 17 2019), belonging to 170 individuals of four different fish species (pearly razorfish, Xyrichtys novacula, $n=166$, length-range: $9-21.7 \mathrm{~cm}$; common pandora, Pagellus erythrinus, $n=2$, lengths: 24.3 and $24.6 \mathrm{~cm}$; stripped seabream, Lithognathus mormyrus, $n=1$, length: $20 \mathrm{~cm}$; and rough ray, Raja radula, $n=1$, length: $34 \mathrm{~cm}$ ). Fishes were captured between 4 and 18 days before using hook and line gear and anesthetized by submersion in a $0.1 \mathrm{~g} \mathrm{~L}^{-1}$ tricaine methanesulfonate (MS-222) solution. Transmitters were implanted in the peritoneal cavity through a small ventral incision, which was then closed with surgical non-absorbable sutures. In the case of the ray, the transmitter was externally attached with a selflocking plastic tag passed through the spiracle. After the tagging procedure, fishes were placed in a tank with clean seawater for recovery until normal behaviour was observed, and were later released in the same zone where they were captured.

\section{Data analysis}

The positioning data obtained from the UMAP software were sequentially filtered to remove system-induced outliers following a methodology similar to the one used in [14]. First, twin positions (i.e., pairs of positions with the same time stamp generated when the positioning algorithm presents more than one possible solution) and positions with large dilution of precision (DOP) values were removed from the original data to generate the "raw dataset". From a pair of twin positions, the position that was further from the previous non-duplicated one was removed from the dataset. DOP is a positioning quality indicator based on the spatial distribution or geometry of receivers in relation to the position of the transmitter [16] and is provided for each position by the UMAP software. Overall, values of DOP $<1$ are considered to be indicators of good estimates, while larger values indicate less reliable positions. At this step, positions with high DOP values $(\mathrm{DOP}>10)$ were considered poor estimates and removed to generate the raw dataset as in [14]. This first filtering discarded 5\% of positions of positioning tests and $3 \%$ of positions from tagged fish.

A more restrictive filtering method was then applied to the raw dataset to generate the "filtered dataset". In this step, positions with DOP $>1$ and positions generating acute spikes in trajectories were removed. Spikes in trajectories were defined as positions in trajectories that deviated from the immediately previous and following ones representing biologically unrealistic movements [33], characterized by turning angles of $<15^{\circ}$ and step lengths of $>15 \mathrm{~m}$ or which involved speeds of $>2 \mathrm{~m} \mathrm{~s}^{-1}$. Finally, the "CTCRW dataset" was generated by fitting a continuous-time correlate random walk (CTCRW) movement model [34] to the filtered dataset and using it to predict temporally regular positions with the same period as transmitters $(2,5$ or $10 \mathrm{~s}$, depending on the model). The CTCRW model was fitted using the crawl package for R [35], setting the positioning error to $3.3 \mathrm{~m}$, overall value that was extracted from the precision of fixed tests.

Regarding the data from tagged fishes, trajectories were divided into chunks of positions separated by gaps of $>30$ min to exclude the periods in which animals were not being detected, because they moved outside the acoustic array or they were buried in the sand (in the specific case of the pearly razorfish [36]). Only chunks with more than 25 positions were included in the analysis. To test the effect of the signal emission period, the calculated results for each tagged fish were divided depending on the used transmitter model: L-AMT-1.421 (period: $10 \mathrm{~s}, n=46)$ ) L-AMT-5.1B (period: $5 \mathrm{~s}, n=96)$; L-AMT5.2 (period: $2 s ; n=24$ ); and L-AMT-8.2 (period: $2 \mathrm{~s}$; $n=4)$.

In order to compare the effect of data post-processing, the obtained datasets ("raw", "filtered" and "CTCRW") were used to calculate the accuracy and precision of positioning test and the efficiency, positioning period, movement rate and speed of both positioning tests and data from tagged fish. The accuracy was calculated for each test as the mean distance between the obtained positions and the coordinates (for fixed tests) or tracks (for drift and towed tests) obtained with the regular portable GPS. The precision was calculated as the mean distance between the obtained positions and the average position of fixed tests (calculated as the peak of a 2-D kernel density distribution of all the points) or the average track of drift and towed tests (obtained by adjusting the CTCRW model to the positions of all the transmitters used in the same test). The positioning efficiency was calculated as the ratio between the obtained positions and the expected number of signals emitted in the same time interval (calculated from the emission period of each transmitter). The positioning period, movement rate and 
speed were calculated as the average time-difference, distance, and speed, respectively, between consecutive positions. In fixed tests, the movement rate was considered to be a false movement rate because, as transmitters were stationary, the observed movements would be only due to the positioning error. In drift and towed tests and in fish trajectories, in contrast, the movement rate was assumed to integrate the false movement rate caused by the positioning error plus the real movement rate caused by the movement of the boat or the fish.

\section{Temporal variation of the acoustic range across the JSATS experiment}

To characterize the natural variability of the acoustic range over long periods of time (i.e., variations induced by changes in the environmental conditions such as the seawater temperature), we used the detections of the beacon signals that were continuously emitted by the receivers throughout the study period. We divided the whole study period (146 days) into 1 -h intervals and calculated the percentage of beacon signals from each receiver that were detected by the rest of receivers in the array, located at known distances from each other. For each day, we fitted a logistic mixed effects regression to model the detection efficiency as function of the distance, considering each beacon id as a random factor, using the nlme package for $\mathrm{R}$ [32]. Then, we used the fixed and random parameters estimated by the model to calculate the mean and receiver-based detection ranges for each day, respectively. The detection range was defined as the distance at which the detection probability dropped below 0.5. Finally, we fitted two linear models to test the relationship between the mean detection range and the daily median and $95 \%$ inter-quantile range of the temperature.

\section{Results}

\section{Acoustic range and optimal receiver array design}

We observed a quick decrease of the detection efficiency when increasing the distance between the receiver and transmitters (non-linear mixed effects logistic model, alpha $=1.60 \pm 0.83 ; \quad$ beta $=-0.05 \pm 0.01, \quad p<0.001)$ (Fig. 2). The mean detection range (i.e., the distance at which the detection probability dropped below 0.5 ) was estimated at $34 \mathrm{~m}$. Below this distance, detection efficiency values of $0.73[0.13-1]$ (median and 95\% interquantile range) were obtained. We observed a high variability on detection efficiency at distances between 35 and $75 \mathrm{~m}$, with a median value of 0.33 [0-0.78]. Some few detections could still be detected at $100 \mathrm{~m}$, with a maximum efficiency of 0.08 (upper end of the $95 \%$ interquantile range).

When we applied the obtained acoustic range model in the simulation study to identify the optimal acoustic

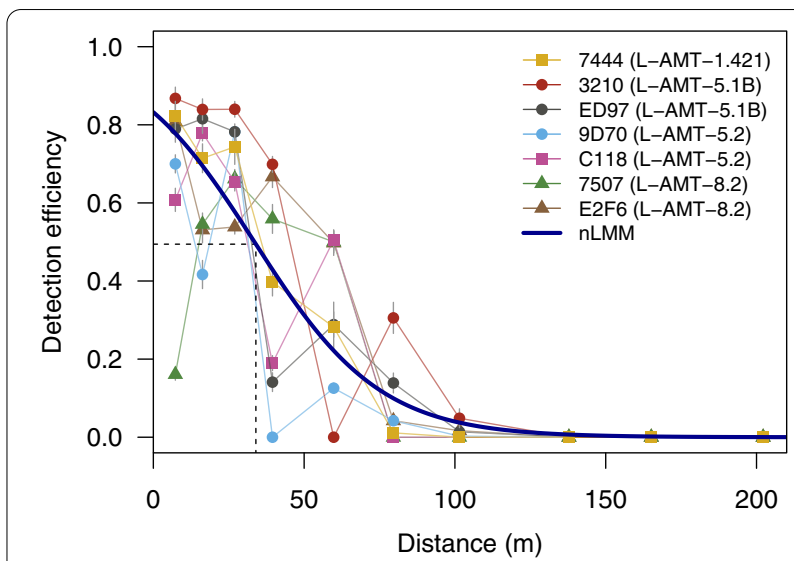

Fig. 2 Results from the range-test analysis conducted in the study site using different models of JSATS AMT transmitters (different colours and symbols). The blue line shows the average result of the logistic mixed effects model (nLMM). Dashed line represents the distance (34 $\mathrm{m}$ ) at which the model predicts a detection efficiency of 0.5

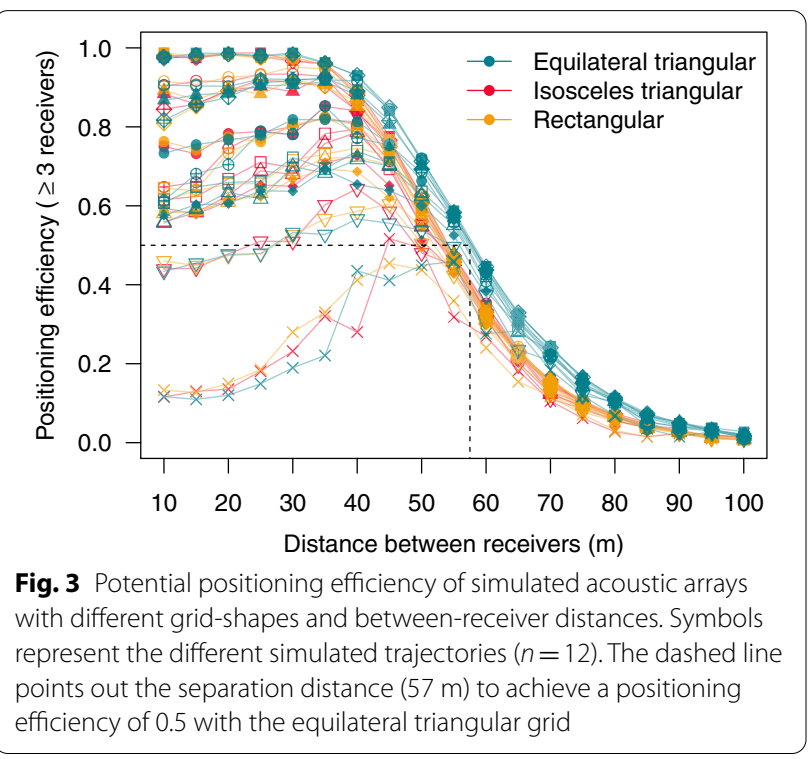

array, we also observed a decrease in the expected positioning efficiency when increasing the distance between the receivers (Fig. 3). Positioning efficiency also decreased when receivers were very close to each other (distance $<30 \mathrm{~m}$ ), because the smaller size of the arrays (restricted to use a maximum of 70 receivers) did not completely cover the extent of simulated trajectories. Small differences were observed between the different grid-shapes. The equilateral triangular geometry presented a slightly higher performance than the isosceles triangular and the rectangular geometries, especially at between-receiver separation distances between 50 and 
$80 \mathrm{~m}$ (Fig. 3). An expected positioning efficiency of 0.5 was obtained at separation distances of around $58 \mathrm{~m}$ with the equilateral triangular grid, and at $53 \mathrm{~m}$ with the other two grid-shapes. Based on these results, an equilateral triangular grid configuration with a between-receiver separation of $50 \mathrm{~m}$ was chosen for the definitive acoustic telemetry array.

\section{Performance of the JSATS receiver array for reality mining approaches}

The UMAP-based positions obtained in the different tests that were carried out in the definitive acoustic array presented a certain degree of scatter, which could be substantially reduced by applying the filtering method and the CTCRW movement model (Fig. 4). The filtering method applied to the raw dataset discarded $16.3 \%$ of the positions, but increased the overall accuracy and precision of the system. This data removal had a very little effect on the overall positioning efficiency of the system (Fig. 5c). After filtering the data, fixed and drift tests showed similar positioning efficiencies of 0.21 [0.03-0.69] (median and 95\% inter-quantile range) and 0.2 [0.06-0.34], respectively. Towed tests, in contrast, showed a lower efficiency (0.03 [0.02-0.08]), meaning that the detection of signals was not very effective during the boat drives, very likely due to propeller and motor noise. Consequently with the positioning efficiency, the observed periods between the obtained positions slightly increased due to the position removal after applying the filter (Fig. 5d). Overall, a median of one signal was effectively positioned every 9.6 [2.9-71.8] s during the fixed tests, every 17.9 [6.6-80.3] s in drift tests, and every 71.4 [41.4-195.9] $\mathrm{s}$ in towed tests. By applying the CTCRW model, positions were interpolated to generate trajectories with fixed time-intervals, and therefore, efficiency values close to one and small positioning periods were obtained (Fig. 5c, d).

After filtering and applying the CTCRW model, the median accuracy of fixed tests was improved from 5.5 [2.6-16.6] $\mathrm{m}$ (median and 95\% inter-quantile range)

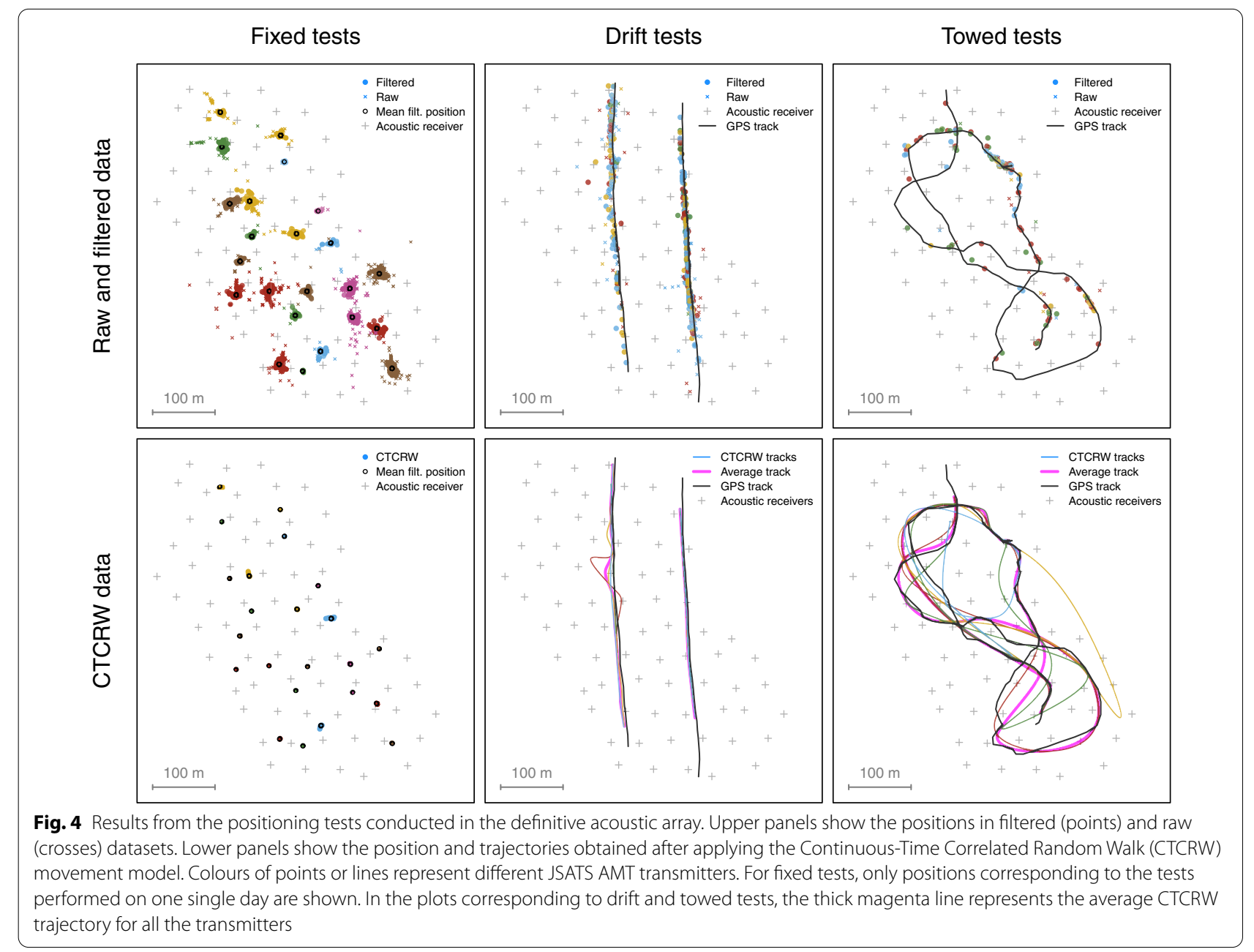



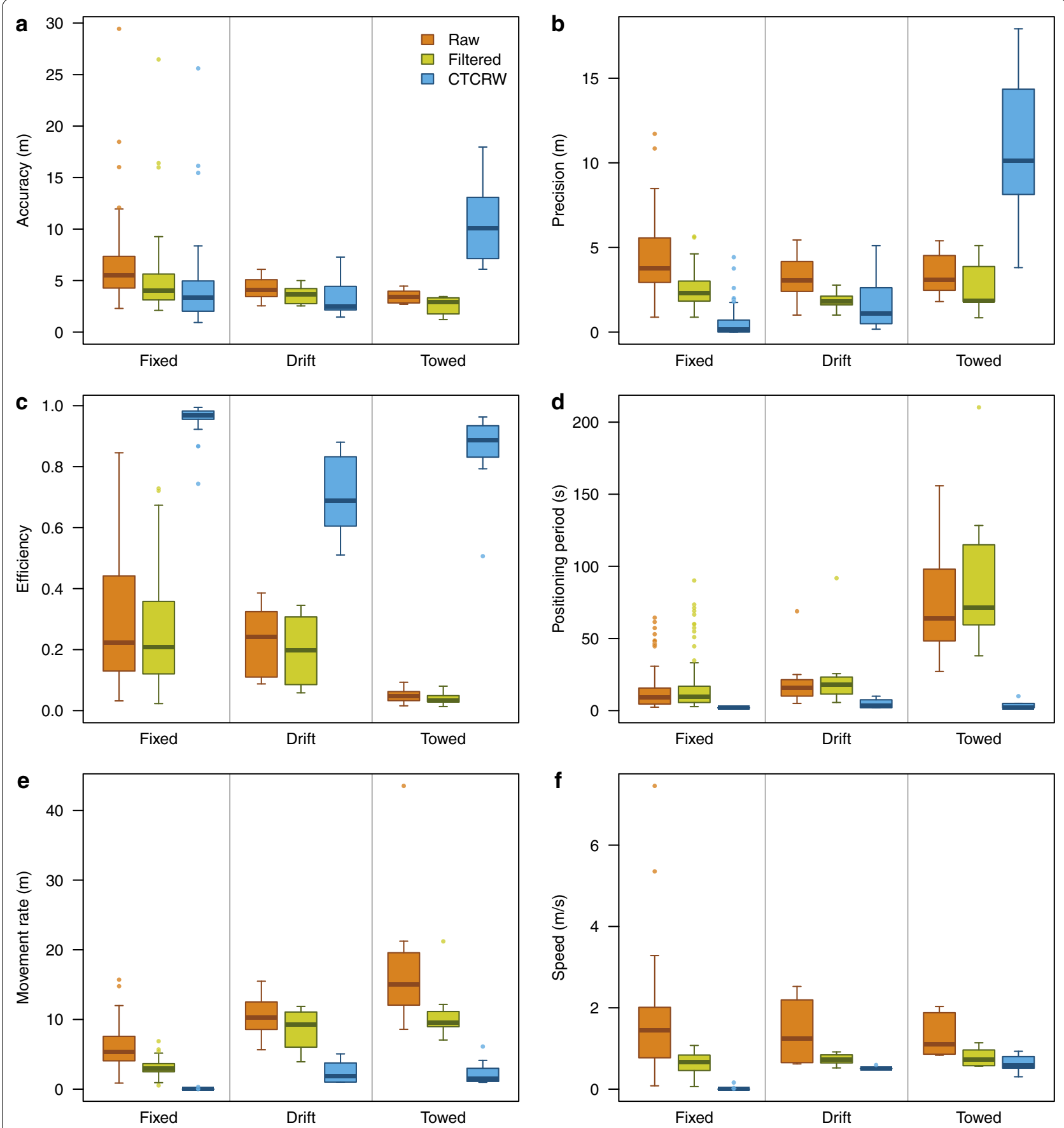

Fig. 5 Accuracy (a), precision (b), positioning efficiency (c), positioning period (d), movement rate (e), and speed (f) of positioning tests before and after applying the trajectory filtering and the Continuous-Time Correlated Random Walk (CTCRW) movement model (different colours). The line in the middle of the box indicates the median, the upper and lower limits of the box represent the interquartile range, whiskers represent values at 1.5 times the interquartile range of the box, and points stand for outliers

to 3.4 [1.1-15.6] m (Fig. 5a), while precision estimates improved from 3.8 [1.1-9.1] $\mathrm{m}$ to 0.2 [0-2.9] m (Fig. 5b). A similar pattern was observed in drift and towed tests, with the exception of the strong decrease in the accuracy and precision observed in the CTCRW dataset of the later (accuracy: 10.1 [6.2-17.1] m; precision: 10.1 [4.517.3] $\mathrm{m})$. Taking into account the lower positioning efficiency observed in towed tests, this decrease of the 
accuracy and precision was very likely due to the cumulative effect of the positions interpolated by the CTCRW model, which did not completely coincide with the GPS or the average tracks used to calculate these variables. However, CTCRW trajectories of towed tests were able to reproduce the main characteristics and tortuosity of the boat tracks (Fig. 4).

Despite being stationary, raw data from fixed tests presented high movement rates and speeds, with median values of $5.4[1-12.7] \mathrm{m}$ and $1.4[0.2-3.8] \mathrm{m} \mathrm{s}^{-1}$, respectively (Fig. 5e, f). Filtering and applying the CTCRW movement model to the data drastically reduced those estimates to values close to zero (CTCRW dataset, movement rate: $6 \cdot 10^{-4}[0-0.05] \mathrm{m}$; speed: $3 \cdot 10^{-4}$ [0-0.02] $\mathrm{m} \mathrm{s}^{-1}$ ). The same pattern was observed in drift and towed tests, where the speed estimates of the raw dataset (1.2 $[0.6-2.5] \mathrm{m} \mathrm{s}^{-1}$ and $1.1[0.8-2] \mathrm{m} \mathrm{s}^{-1}$, respectively) were reduced to values of 0.5 [0.5-0.6] $\mathrm{m} \mathrm{s}^{-1}$ and 0.6 [0.3-0.9] $\mathrm{m} \mathrm{s}^{-1}$ in the CTCRW dataset, getting closer to the speeds measured from the GPS tracks (drift tests: 0.5 [0.4-0.8] $\mathrm{m} \mathrm{s}^{-1}$; towed tests: $\left.0.8[0.3-1.9] \mathrm{m} \cdot \mathrm{s}^{-1}\right)$.

\section{Fish trajectories generated by the JSATS system}

The raw dataset obtained from all tagged fish contained a total of 864,142 UMAP-based positions, corresponding to a single tracking day, from which $9.8 \%$ was discarded after applying the filtering protocol. The trajectories of each species reflected their different movement ranges (Fig. 6 and Additional file 3). For instance, the movements of most pearly razorfish individuals were restricted to a radius of a few meters, while the rough ray moved across the entire receiver array (Fig. 6). However, analysing and comparing the movement patterns of different species did not fall within the objectives of this study, and

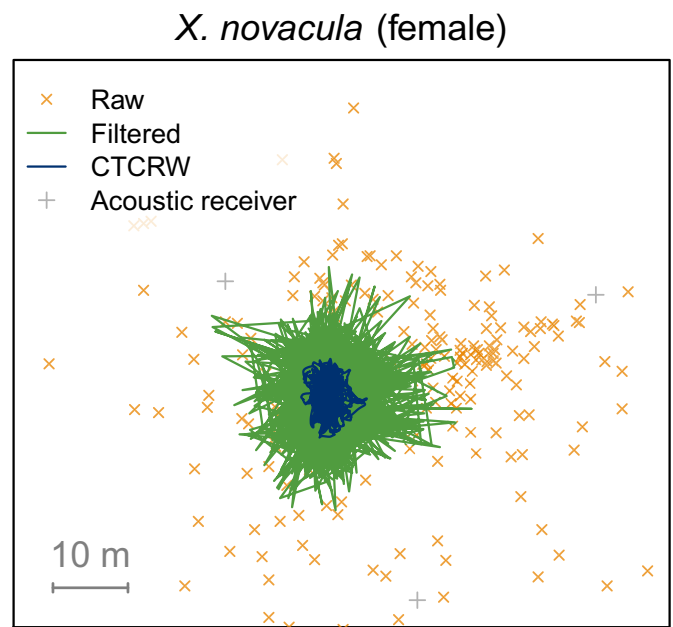

P. erythrinus

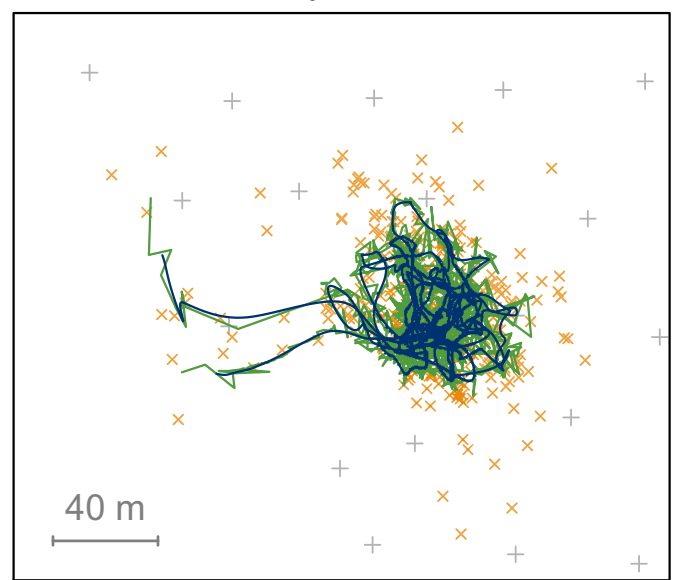

X. novacula (male)

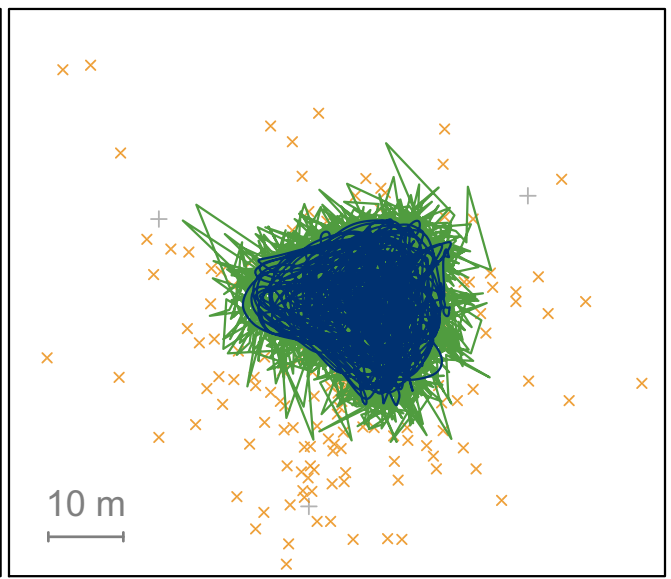

R. radula (female)

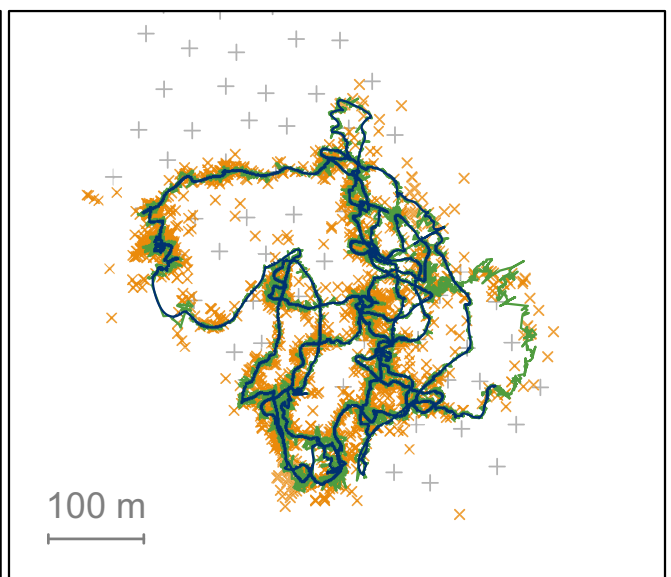

Fig. 6 Trajectories of four different individuals from different species tagged with JSATS AMT transmitters. Green lines represent the trajectories of the filtered dataset, orange crosses indicate the positions discarded from the raw dataset and the blue line corresponds to the trajectory after applying the Continuous-Time Correlated Random Walk (CTCRW) movement model 

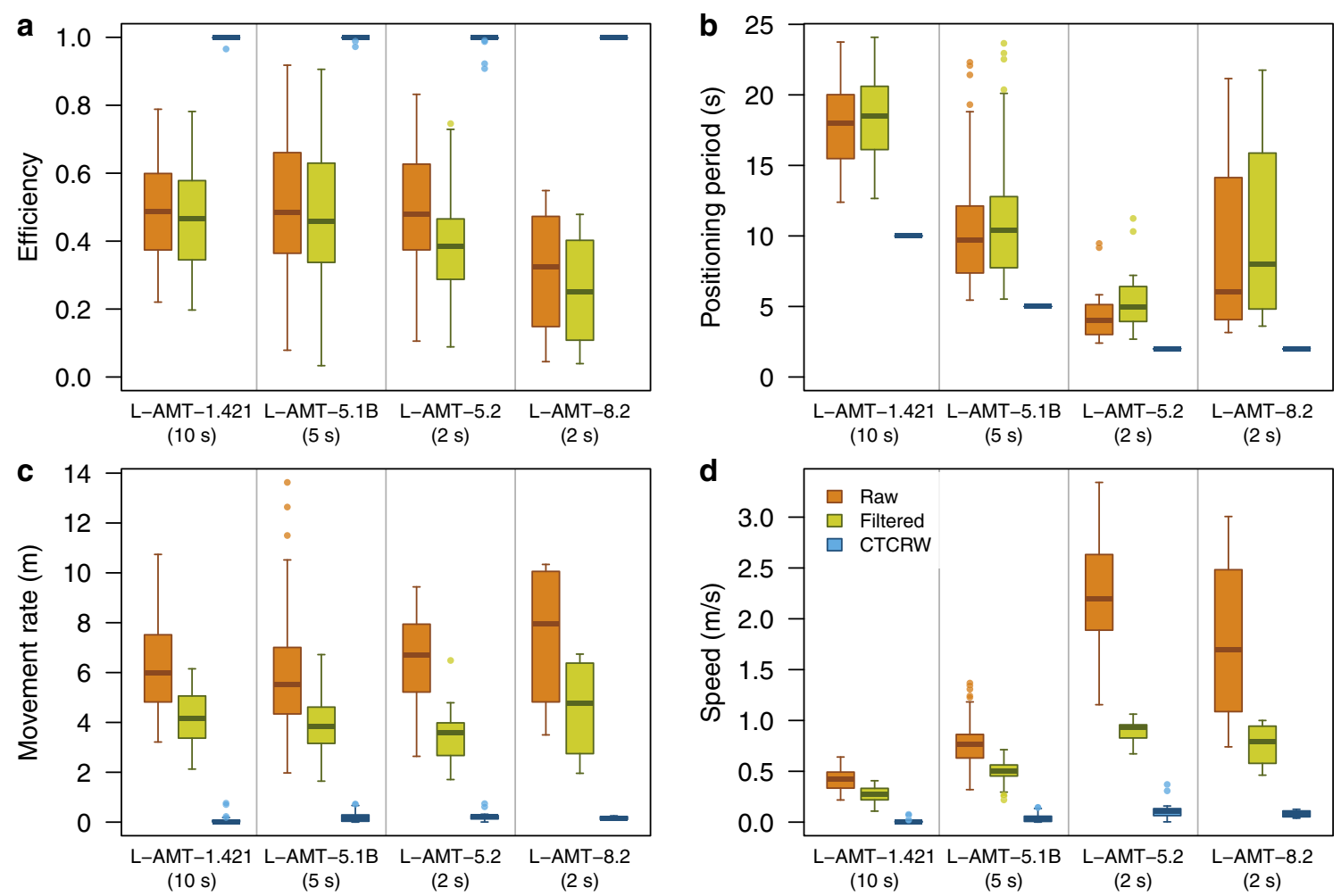

Fig. 7 Positioning efficiency $(\mathbf{a})$, positioning period $(\mathbf{b})$, movement rate $(\mathbf{c})$, and speed $(\mathbf{d})$ of the positions of tagged fishes before and after applying the trajectory filtering and the Continuous-Time Correlated Random Walk (CTCRW) movement model (different colours), separated by transmitter model. The line in the middle of the box indicates the median, the upper and lower limits of the box represent the interquartile range, whiskers represent values at 1.5 times the interquartile range of the box, and points stand for outliers

thus, the following analyses were focused on the effect of the transmitter model and the emission period.

A median positioning efficiency of $0.48[0.12-0.84]$ was obtained in the raw dataset, slightly reduced to $0.45[0.1-$ 0.81 ] after filtering the data (Fig. 7a). We did not observe any statistical difference on efficiency between the different transmitter models (raw dataset: one-way ANOVA, $\mathrm{F}(3,166)=1.141, p=0.334$; filtered dataset: one-way ANOVA, $\mathrm{F}(3,166)=2.216, p=0.088)$. In concordance with the observed efficiency, the average positioning periods were close to twice the emission period of each transmitter (Fig. 7b), with values in the filtered dataset ranging from 5 [2.7-20.7] s (L-AMT-5.2, emission period: $2 \mathrm{~s}$ ) to 18.5 [12.7-23.5] s (L-AMT-1.421, emission period of $10 \mathrm{~s})$.

The movement rates and speeds estimated for all the transmitter models were drastically reduced after filtering and, especially, applying the CTCRW model (Fig. 7c, d). We did not found significant differences between the movement rates calculated for the different transmitters with either the raw dataset (one-way ANOVA, $\mathrm{F}(3,166)=0.905, p=0.44)$ or the filtered dataset (oneway ANOVA, $\mathrm{F}(3,166)=2.484, p=0.0626)$. A median movement rate of $5.8 \mathrm{~m}$ [2.6-10.5 m] was obtained in

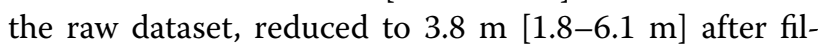
tering the data (Fig. $7 \mathrm{c}$ ). The movement rate values obtained in the CTCRW dataset, in contrast, presented significant differences between transmitter models (oneway $\operatorname{ANOVA,~} \mathrm{F}(3,166)=10.66, p<0.001)$, despite the observed differences were very small, ranging from 0.02 [0-0.65] m (L-AMT-1.421) to 0.21 [0-0.67] m (L-AMT5.1B). The transmitter model had a significant effect on the speeds estimated in all the datasets (one-way ANOVA, raw dataset: $\mathrm{F}(3,166)=216.1, p<0.001$; filtered dataset: $\mathrm{F}(3,166)=181.4, p<0.001$; CTCRW dataset: $\mathrm{F}(3,166)=40.73, p<0.001)$. Overall, larger speeds were observed in transmitters with the emission period of $2 \mathrm{~s}$ (L-AMT-5.2 and L-AMT-8.2), with median values of 2.2 [1.3-3.1] $\mathrm{m} \mathrm{s}^{-1}$ and $1.7[0.8-2.9] \mathrm{m} \mathrm{s}^{-1}$ in the raw dataset, respectively, but drastically reduced to $0.1[0-0.3] \mathrm{m}$ $\mathrm{s}^{-1}$ and 0.08 [0.04-0.12] $\mathrm{m} \mathrm{s}^{-1}$ in the CTCRW dataset (Fig. 7d). The lowest speeds were observed in the transmitters with the emission of $10 \mathrm{~s}$ (L-AMT-1.421), with a median value of $0.4[0.2-0.6] \mathrm{m} \cdot \mathrm{s}^{-1}$ in the raw dataset and $0.002[0-0.065] \mathrm{m} \cdot \mathrm{s}^{-1}$ in the CTCRW dataset (Fig. 7d). 

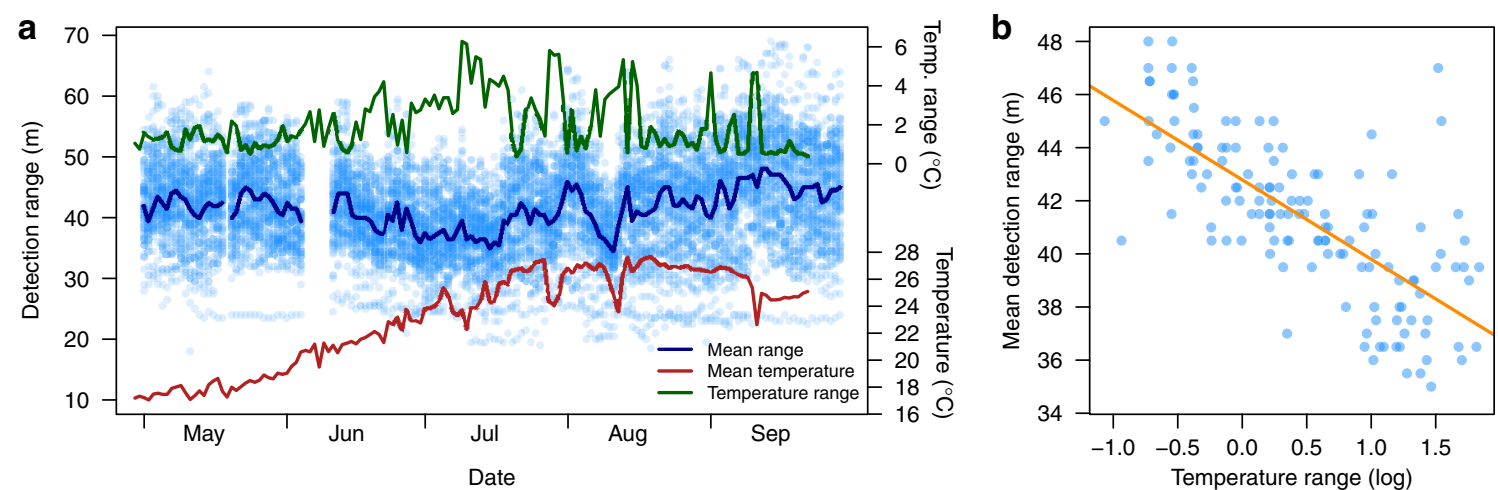

Fig. 8 Temporal variation of the detection range of the JSATS system in the waters of Mallorca Island (a) and the relationship between the daily mean detection range and the standard deviation of temperature $(\mathbf{b})$. The blue line in a represents the mean range predicted by the non-linear mixed effects models, and the points represent the range predicted for each beacon signal id. The orange line in $\mathbf{b}$ represents the linear model fitted to the data

\section{Temporal variation of the acoustic range during the JSATS experiment}

A significant variation of the acoustic range was observed during the study period (Fig. 8a), with detection ranges ranging from 26 to $56 \mathrm{~m}$ (95\% inter-quantile range for all the estimated ranges per day and beacon id), with a median of $42 \mathrm{~m}$. The relationship between the mean daily range and the mean daily temperature was not significant (linear regression, $\mathrm{F}(1,135)=0.034, p=0.853)$. However, when we tested the effect of the $95 \%$ inter-quantile range of the temperature, a proxy for the temperature variability within a day, we found a negative significant relationship (linear regression, $\mathrm{F}(1,135)=152.2, p<0.001$, $R^{2}=0.53$ ) (Fig. 8b).

\section{Discussion}

Our study is the first exploring the performance of a highresolution acoustic telemetry system in an open marine environment, demonstrating that these systems can be effectively used to track the movements of large amounts of individuals simultaneously. This included tracking small-sized fish (the smallest tagged individual was $9 \mathrm{~cm}$ in length) and efficient position generation (around half of the emitted signals were successfully positioned) with sub-meter precision (after post-processing the data) and a temporal resolution of few seconds. However, we detected some limitations of high-resolution telemetry systems when this technique is used in marine environments, which should be carefully taken into account when planning and designing further experiments.

Our results evidenced that the acoustic range of highfrequency $(416.7 \mathrm{kHz})$ signals of the JSATS system is greatly reduced in saltwater, imposing an important restriction for telemetry experiments in terms of area that can be covered with a limited amount of receivers.
The acoustic range observed during the preliminary range-test $(34 \mathrm{~m})$ and throughout the experiment using receiver's beacon signals $(42 \mathrm{~m})$, is much smaller than the 110-120 $\mathrm{m}$ range reported for the same system in freshwater environments [20]. Previous studies using BPSK or PPM systems working at $180 \mathrm{kHz}$ in freshwater environments showed even larger acoustic ranges of

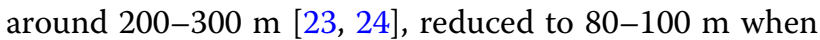
applied in the coastal ocean [37]. In comparison, the usual $69 \mathrm{kHz}$ PPM systems used in coastal marine environments usually report an acoustic range between 150 and $300 \mathrm{~m}$ [38, 39]. Overall, the main advantage of highfrequency systems over systems working at lower frequencies resides in the smaller size of their piezoceramics and the shorter duration of their signals, which allow the production of smaller transmitters and the simultaneous tracking of a larger number of individuals, but in return, present smaller acoustic ranges. Therefore, the selection of the acoustic telemetry system depends on the characteristics of the study species and the research question to be addressed.

The acoustic range might be affected by the physical characteristics of the water column [26, 27]. By conducting a long-term acoustic range study using the beacon signals from receivers, we were able to characterize the variations of the acoustic range caused by the natural environmental variability. We found a negative relationship between the daily mean detection range and the daily temperature range, a parameter that was related to the oscillations of the thermocline. This means that nonstable conditions at within day level might impact the overall performance of the JSATS system. In our study site, this resulted in a maximum variation of $\sim 10 \mathrm{~m}$ in the average detection range, which was not dramatic. However, changing hydrodynamic conditions is a factor that 
must be considered in future deployments of this system in other marine environments. Other factors that are also known to affect the acoustic range could not be tested in our study, such as the effect of environmental noise, habitat heterogeneity or the receiver set up. It has been described that BPSK coding systems are less affected by environmental noise than PPM systems, because the shorter duration of the signals reduces the probability of interferences [24]. It is also known that the presence of complex habitats, such as coral reefs or dense vegetation, lower the detection and positioning efficiency of acoustic telemetry systems $[14,39]$. The combination between physical factors and the receiver set up also can also affect the acoustic range, for instance, by currents modifying the receiver tilt angle in receivers fixed to ropes or buoys [40]. Given all these factors, it is greatly important to adequate the settings of the acoustic array to local environments and conducting exhaustive tests before starting a study [41]. In this sense, conducting long-term range tests extending on several days or using fixed sentinel transmitters or beacon signals from receivers is highly recommendable to better understand the variability of the acoustic range and to assess the overall performance of the telemetry array $[31,40]$.

Computer simulation studies, complemented with in situ tests, are a very suitable tool to adapt and evaluate the optimal acoustic arrays to the specific local conditions and the disposable material [42]. Our simulation of the performance of receiver grids with different shapes and between-receiver distances allowed us to select the design that was later used, where receivers were separated by $50 \mathrm{~m}$ forming an equilateral triangular grid. Using this setting, our simulation predicted a positioning efficiency of 0.5 , very close to the median efficiency that was later obtained from tagged fishes (0.48). We used a simple simulation model for our predictions, only based on the acoustic range model obtained during the preliminary range tests, but more complex models could be used in the future to include the factors affecting the acoustic range mentioned above.

Positioning systems using hyperbolic multilateration are subject to system-induced outliers that might hinder the real characteristics of the underlying trajectories. Therefore, applying filtering methods and movement models is highly recommended before analysing the trajectories [14, 24, 33, 43]. The accuracy and precision of the positions obtained in our system greatly improved after applying the trajectory filter, which discarded $10-16 \%$ of the original positions, but without reaching the sub-meter values observed in other studies [23, 24]. By consecutively applying the CTCRW model, we further improved the accuracy and precision in the fixed tests, reaching accuracy values that were within the accuracy of the GPS used to take the reference positions (3-5 m) and a sub-meter precision. Moreover, we were able to reproduce the trajectory of the boat in drift and towed tests. The CTCRW model drastically reduced the false movement rate of all the obtained trajectories and provided more realistic speed estimates. Moreover, the CTCRW model also allows the interpolation of missing positions to obtain trajectories with regular time-intervals, so that they can be later analysed using methods that require this type of trajectories (e.g. Hidden Markov Models, [44]).

\section{Conclusions}

Our study demonstrates that high-resolution telemetry systems (such as the JSATS system) are an effective method to monitor the movements of natural fish populations in marine environments. Due to the restricted acoustic range, it is obvious that these systems are not suited for species that perform migrations or have large home ranges. However, most marine coastal species are highly resident, with home range areas smaller than $1 \mathrm{~km}^{2}$ [45]. Therefore, these systems might be applied to many different species in marine systems, not only restricted to fish but also to other taxa such as jellyfish, sea urchins and starfish, among others, due to the small size of the tags, or focusing on specific life-story phases of mobile animals (e.g. spawning grounds). At the present, the JSATS system offers a novel methodology for tracking marine fish behaviour at high-resolution scale for resident species, with a great potential to address still poorly known individual and population processes such as mating behaviours, social interactions, collective movements or micro-habitat use.

\section{Supplementary information}

The online version contains supplementary material available at https://doi. org/10.1186/s40317-020-00224-w.

Additional file 1. Plot of examples of the simulated acoustic arrays, generated with different grid-shapes (rows) and distances between receivers (rows). The yellow polygon represents the extent of the study area that should be covered. Each panel indicates the number of receivers (N), restricted to a maximum of 70, and an estimation of the area covered by each array.

Additional file 2. Plot of simulations of fish trajectories used to test the efficiency of the different acoustic arrays. The yellow polygon represents the extent of the study area that should be covered. Each panel indicates the main parameters used in the simulation: the rate of exploitation ( $k$ ) and the radius of the home range $(r)$.

Additional file 3. Animation of the trajectories belonging to 170 individuals obtained with the JSATS high-resolution acoustic telemetry system in one tracking day (May 17 2019) within the Bay of Palma marine reserve (Balearic Islands, NW Mediterranean Sea). Positions were filtered and smoothed using a continuous-time correlated random walk movement model. The visualization was generated with the 'moveVis' package for $\mathrm{R}$ [46]. 


\section{Abbreviations}

BPSK: Binary Phase-Shift Keying; CTCRW: Continuous-time-correlated random walk; DOP: Dilution of precision; JSATS: Juvenile Salmon Acoustic Telemetry System; PPM: Pulse position modulation.

\section{Acknowledgements}

We would like to thank David Gambin and the staff from Lotek Wireless Inc. for their support since the beginning of this study. We would also like to thank Sebastiá Cabanellas and Christopher Monk for their support during the field work. We acknowledge support of the publication fee by the CSIC Open Access Publication Support Initiative through its Unit of Information Resources for Research (URICI).

\section{Authors' contributions}

$E A, J A$ and RA conceived the study. RA provided the telemetry material. EA $\mathrm{JA}, \mathrm{MMB}, \mathrm{GFB}, \mathrm{ACC}$, and $\mathrm{AL}$ conducted the telemetry experiments. EA led the data analysis and wrote the first manuscript. All authors made significant comments to the manuscript. All authors read and approved the final manuscript.

\section{Funding}

The telemetry system was financed by the German Federal Ministry of Education and Research (grant no. \#033W024A). EA was supported by a Margalida Comas postdoctoral grant from the Government of the Balearic Islands and the European Social Fund (Grant No. PD/023/2018). JA was supported by a Ramon y Cajal Grant (Grant No. RYC2018-024488-I) and received funding from the CLOCKS R\&D Project (Grant No. PID2019-104940GA-I00) and the intramural research project JSATS (Grant No. PIE 202030E002) funded by the Spanish Ministry of Science and Innovation and the Spanish National Research Council. GFB was supported by a Ph.D. fellowship (FPI-INIA 2015-0013-CPD2015-0084) from the National Institute for Agricultural and Food Research and Technology.

\section{Availability of data and materials}

The dataset supporting the conclusions of this article as well as the R scripts used for the analysis are available in an open Figshare repository (https:// doi.org/10.6084/m9.figshare.13264796). The metadata of the "JSATS-PalmaBay-2019" acoustic telemetry project is stored in the European Telemetry Network open database (https://lifewatch.be/ETN/).

\section{Ethics approval and consent to participate}

The tagging protocol followed the guidelines provided by the Spanish Government (RD 53/2013) and was approved by the Committee on the Ethics of Animal Experimentation of the University of the Balearic Islands (Ref. CEEA 107/01/19). The Department of Environment, Agriculture and Fisheries of the Government of the Balearic Islands granted permissions for fishing, operating and releasing the animals in the Bay of Palma marine reserve.

\section{Consent for publication}

Not applicable.

\section{Competing interests}

The authors declare that they have no competing interests.

\begin{abstract}
Author details
${ }^{1}$ Institut Mediterrani d'Estudis Avançats (IMEDEA, UIB-CSIC), Esporles, Balearic Islands, Spain. ${ }^{2}$ Department of Biology and Ecology of Fishes, Leibniz-Institute of Freshwater Ecology and Inland Fisheries, Berlin, Germany. ${ }^{3}$ Division of Integrative Fisheries Management, Faculty of Life Sciences, Humboldt-Universität zu Berlin, Berlin, Germany. ${ }^{4}$ Laboratori d'Investigacions Marines i Aqüicultura (LIMIA), Govern de les Illes Balears, Port d'Andratx, Balearic Islands, Spain.
\end{abstract}

Received: 24 September 2020 Accepted: 3 December 2020 Published online: 04 January 2021

\section{References}

1. Eagle N, Pentland A. Reality mining: sensing complex social systems. PersUbiquit Comput. 2006;10:255-68. https://doi.org/10.1007/s0077 9-005-0046-3.
2. Krause J, Krause S, Arlinghaus R, Psorakis I, Roberts S, Rutz C. Reality mining of animal social systems. Trends EcolEvol. 2013;28:541-51. https://doi. org/10.1016/j.tree.2013.06.002.

3. Kays R, Crofoot MC, Jetz W, Wikelski M. Terrestrial animal tracking as an eye on life and planet. Science. 2015;348:2478. doi: https://doi. org/10.1126/science.aaa2478.

4. Strandburg-Peshkin A, Farine DR, Couzin ID, Crofoot MC. Shared decision-making drives collective movement in wild baboons. Science. 2015;348:1358-61. https://doi.org/10.1126/science.aaa5099.

5. King AJ, Fehlmann G, Biro D, Ward AJ, Fürtbauer I. Re-wilding collective behaviour: an ecological perspective. Trends Ecol Evol. 2018;33:347-57. https://doi.org/10.1016/j.tree.2018.03.004.

6. Hussey NE, Kessel ST, Aarestrup K, Cooke SJ, Cowley PD, Fisk AT, et al. Aquatic animal telemetry: a panoramic window into the underwater world. Science. 2015;348:1255642. https://doi.org/10.1126/science.12556 42.

7. Heupel MR, Semmens JM, Hobday AJ. Automated acoustic tracking of aquatic animals: scales, design and deployment of listening station arrays. Mar Freshw Res. 2006;57:1-13. https://doi.org/10.1071/MF05091.

8. Simpfendorfer CA, Heupel MR, Collins AB. Variation in the performance of acoustic receivers and its implication for positioning algorithms in a riverine setting. Can J Fish Aquat Sci. 2008;65:482-92. https://doi.org/10.1139/ f07-180.

9. Simpfendorfer CA, Heupel MR, Hueter RE. Estimation of short-term centers of activity from an array of omnidirectional hydrophones and its use in studying animal movements. Can J Fish Aquat Sci. 2002;59:23-32. https://doi.org/10.1139/f01-191.

10. Pedersen MW, Weng KC. Estimating individual animal movement from observation networks. Methods EcolEvol. 2013;4:920-9. https://doi. org/10.1111/2041-210X.12086.

11. Alós J, Palmer M, Balle S, Arlinghaus R. Bayesian state-space modelling of conventional acoustic tracking provides accurate descriptors of home range behavior in a small-bodied coastal fish species. PLOS ONE. 2016;11:e0154089. https://doi.org/10.1371/journal.pone.0154089.

12. Finn JT, Brownscombe JW, Haak CR, Cooke SJ, Cormier R, Gagne T, et al. Applying network methods to acoustic telemetry data: Modeling the movements of tropical marine fishes. Ecol Modell. 2014;293:139-49. https ://doi.org/10.1016/j.ecolmodel.2013.12.014.

13. Aspillaga E, Safi K, Hereu B, Bartumeus F. Modelling the threedimensional space use of aquatic animals combining topography and Eulerian telemetry data. Methods EcolEvol. 2019;10:1551-7. https://doi. org/10.1111/2041-210X.13232.

14. Baktoft H, Zajicek P, Klefoth T, Svendsen JC, Jacobsen L, Pedersen MW, et al. Performance assessment of two whole-lake acoustic positional telemetry systems - is reality mining of free-ranging aquatic animals technologically possible? PLoS ONE. 2015;10:e0126534. https://doi. org/10.1371/journal.pone.0126534.

15. Monk CT, Arlinghaus R. Eurasian perch, Perca fluviatilis, spatial behaviour determines vulnerability independent of angler skill in a whole-lake reality mining experiment. Can J Fish Aquat Sci. 2018;75:417-28. https://doi. org/10.1139/cjfas-2017-0029.

16. Niezgoda G, Benfield M, Sisak M, Anson P. Tracking acoustic transmitters by code division multiple access (CDMA)-based telemetry. Hydrobiologia. 2002;483:275-86. https://doi.org/10.1007/978-94-017-0771-8_32.

17. Roy R, Beguin J, Argillier C, Tissot L, Smith F, Smedbol S, et al. Testing the VEMCO Positioning System: spatial distribution of the probability of location and the positioning error in a reservoir. Anim Biotelemetry. 2014;2:1. https://doi.org/10.1186/2050-3385-2-1.

18. Biesinger Z, Bolker BM, Marcinek D, Grothues TM, Dobarro JA, Lindberg WJ. Testing an autonomous acoustic telemetry positioning system for fine-scale space use in marine animals. J Exp Mar Bio Ecol. 2013;448:4656. https://doi.org/10.1016/j.jembe.2013.06.007.

19. Baktoft $H$, Gjelland KØ, Økland F, Thygesen UH. Positioning of aquatic animals based on time-of-arrival and random walk models using YAPS (Yet Another Positioning Solver). Sci Rep. 2017;7:14294. https://doi. org/10.1038/s41598-017-14278-z.

20. Weiland MA, Deng ZD, Seim TA, LaMarche BL, Choi EY, Fu T, et al. A cabled acoustic telemetry system for detecting and tracking juvenile salmon: part 1. Engineering design and instrumentation. Sensors. 2011;11:564560. https://doi.org/10.3390/s110605645. 
21. Simpfendorfer CA, Huveneers C, Steckenreuter A, Tattersall K, Hoenner $X$, Harcourt R, et al. Ghosts in the data: false detections in VEMCO pulse position modulation acoustic telemetry monitoring equipment. Anim Biotelemetry. 2015;3:55. https://doi.org/10.1186/s40317-015-0094-z.

22. Edelhoff H, Signer J, Balkenhol N. Path segmentation for beginners: an overview of current methods for detecting changes in animal movement patterns. MovEcol. 2016;4:21. https://doi.org/10.1186/s40462-016-0086-5.

23. Guzzo MM, Van Leeuwen TE, Hollins J, Koeck B, Newton M, Webber DM, et al. Field testing a novel high residence positioning system for monitoring the fine-scale movements of aquatic organisms. Methods EcolEvol. 2018;9:1478-88. https://doi.org/10.1111/2041-210X.12993.

24. Leander J, Klaminder J, Jonsson M, Brodin T, Leonardsson K, Hellström G. The old and the new: Evaluating performance of acoustic telemetry systems in tracking migrating Atlantic salmon (Salmo salar) smolt and European eel (Anguilla anguilla) around hydropower facilities. Can J Fish Aquat Sci. 2020;77:177-87. https://doi.org/10.1139/cjfas-2019-0058.

25. Ainslie MA, McColm JG. A simplified formula for viscous and chemical absorption in sea water. J AcoustSoc Am. 1998;103:1671. https://doi. org/10.1121/1.421258.

26. Huveneers C, Simpfendorfer CA, Kim S, Semmens JM, Hobday AJ, Pederson $\mathrm{H}$, et al. The influence of environmental parameters on the performance and detection range of acoustic receivers. Methods EcolEvol. 2016;7:825-35. https://doi.org/10.1111/2041-210X.12520.

27. Steel A, Coates JH, Hearn AR, Klimley AP. Performance of an ultrasonic telemetry positioning system under varied environmental conditions. AnimBiotelem. 2014;2:15. https://doi.org/10.1186/2050-3385-2-15.

28. McMichael GA, Eppard MB, Carlson TJ, Carter JA, Ebberts BD, Brown RS, et al. The Juvenile Salmon Acoustic Telemetry System: a new tool. Fisheries. 2010;35:9-22. https://doi.org/10.1577/1548-8446-35.1.9.

29. R Core Team. R: A Language and Environment for Statistical Computing, version 4.0.3. R Foundation for Statistical Computing, Vienna, Austria. 2020. URL: https://www.r-project.org/

30. Alós J, Palmer M, Rosselló R, Arlinghaus R. Fast and behavior-selective exploitation of a marine fish targeted by anglers. Sci Rep. 2016;6:38093. https://doi.org/10.1038/srep38093.

31. Kessel ST, Cooke SJ, Heupel MR, Hussey NE, Simpfendorfer CA, Vagle $S$, et al. A review of detection range testing in aquatic passive acoustic telemetry studies. Rev Fish Biol Fish. 2014;24:199-218. https://doi. org/10.1007/s11160-013-9328-4.

32. Pinheiro J, Bates D, DebRoy S, Sarkar D, R Core Team. nlme: Linear and Nonlinear Mixed Effects Models. R package version 3.1-149. 2020. URL: https://cran.r-project.org/package=nlme

33. Freitas C, Lydersen C, Fedak MA, Kovacs KM. A simple new algorithm to filter marine mammal Argos locations. Mar Mamm Sci. 2008;24:315-25. https://doi.org/10.1111/j.1748-7692.2007.00180.x.

34. Johnson DS, London JM, Lea MA, Durban JW. Continuous-time correlated random walk model for animal telemetry data. Ecology. 2008;89:1208-15. https://doi.org/10.1890/07-1032.1.

35. Johnson DS, London JM. crawl: an R package for fitting continuous-time correlated random walk models to animal movement data. $\mathrm{R}$ package version 2.2.1. 2018. URL: https://doi.org/10.5281/zenodo.596464
36. Alós J, Martorell-Barceló M, Campos-Candela A. Repeatability of circadian behavioural variation revealed in free-ranging marine fish. R Soc Open Sci. 2017;4:160791. https://doi.org/10.1098/rsos.160791.

37. Rechisky EL, Porter AD, Winchell PM, Welch DW. Performance of a highfrequency $(180 \mathrm{kHz})$ acoustic array for tracking juvenile Pacific salmon in the coastal ocean. AnimBiotelem. 2020;8:19. https://doi.org/10.1186/ s40317-020-00205-Z.

38. Aspillaga E, Bartumeus F, Linares C, Starr RM, López-Sanz À, Díaz $D$, et al. Ordinary and extraordinary movement behaviour of small resident fish within a Mediterranean marine protected area. PLoS ONE. 2016;11:e0159813. https://doi.org/10.1371/journal.pone.0159813.

39. Swadling DS, Knott NA, Rees MJ, Pederson H, Adams KR, Taylor MD, et al. Seagrass canopies and the performance of acoustic telemetry: Implications for the interpretation of fish movements. AnimBiotelem. 2020;8:8. https://doi.org/10.1186/s40317-020-00197-w.

40. Reubens J, Verhelst P, van der Knaap I, Deneudt K, Moens T, Hernandez F. Environmental factors influence the detection probability in acoustic telemetry in a marine environment: results from a new setup. Hydrobiologia. 2019;845:81-94. https://doi.org/10.1007/s10750-017-3478-7.

41. Brownscombe JW, Lédée EJI, Raby GD, Struthers DP, Gutowsky LFG, Nguyen VM, et al. Conducting and interpreting fish telemetry studies: considerations for researchers and resource managers. Rev Fish Biol Fish. 2019;29:369-400. https://doi.org/10.1007/s11160-019-09560-4.

42. Kraus RT, Holbrook CM, Vandergoot CS, Stewart TR, Faust MD, Watkinson DA, et al. Evaluation of acoustic telemetry grids for determining aquatic animal movement and survival. Methods EcolEvol. 2018;9:1489-502. https://doi.org/10.1111/2041-210X.12996.

43. Meckley TD, Holbrook CM, Wagner CM, Binder TR. An approach for filtering hyperbolically positioned underwater acoustic telemetry data with position precision estimates. AnimBiotelem. 2014;2:7. https://doi. org/10.1186/2050-3385-2-7.

44. Michelot T, Langrock R, Patterson TA. moveHMM: an R package for the statistical modelling of animal movement data using hidden Markov models. Methods EcolEvol. 2016;7:1308-15. https://doi. org/10.1111/2041-210X.12578.

45. Di Franco A, Plass-Johnson JG, Di Lorenzo M, Meola B, Claudet J, Gaines $\mathrm{SD}$, et al. Linking home ranges to protected area size: The case study of the Mediterranean Sea. Biol Conserv. 2018;221:175-81. https://doi. org/10.1016/j.biocon.2018.03.012.

46. Schwalb-Willmann J, Remelgado R, Safi K, Wegmann M. moveVis: Animating movement trajectories in synchronicity with static or temporally dynamic environmental data in R. Methods EcolEvol. 2020;11:664-9. https://doi.org/10.1111/2041-210X.13374.

\section{Publisher's Note}

Springer Nature remains neutral with regard to jurisdictional claims in published maps and institutional affiliations.

\footnotetext{
Ready to submit your research? Choose BMC and benefit from:

- fast, convenient online submission

- thorough peer review by experienced researchers in your field

- rapid publication on acceptance

- support for research data, including large and complex data types

- gold Open Access which fosters wider collaboration and increased citations

- maximum visibility for your research: over 100M website views per year
}

At $\mathrm{BMC}$, research is always in progress.

Learn more biomedcentral.com/submissions 